\title{
EMPREENDEDORISMO PÚBLICO NA GESTÃO MUNICIPAL: O CASO DA SECRETARIA MUNICIPAL DO DESENVOLVIMENTO ECONÔMICO DE FORTALEZA-CE
}

Regislene De Oliveira Freitas Regislene De Oliveira Freitas ${ }^{1}$ Alexandre Oliveira Lima ${ }^{2}$ Antonia Márcia Sousa ${ }^{3}$

Sandra Maria Guimarães Callado²

\footnotetext{
${ }^{1}$ Universidade Federal da Integração Latino Americana

${ }^{2}$ Universidade da Integração Internacional da Lusofonia Afro-Brasileira

${ }^{3}$ Universidade Federal do Ceara
} 


\section{EMPREENDEDORISMO PÚBLICO NA GESTÃO MUNICIPAL: O CASO DA SECRETARIA MUNICIPAL DO DESENVOLVIMENTO ECONÔMICO DE FORTALEZA-CE}

\section{RESUMO}

Esta pesquisa tem como objetivo analisar a inserção de aspectos do empreendedorismo no setor público por meio do estudo das ações e ferramentas utilizadas na gestão da Secretaria Municipal do Desenvolvimento Econômico (SDE) de Fortaleza-CE. O estudo possui natureza qualitativa, por meio de entrevista semiestruturada, pesquisa bibliográfica e documental. Os resultadosdemonstram que a SDE utiliza ferramentas inovadoras, como o MAPPFOR, o Plano Fortaleza 2040 e os softwares de mapeamento socioeconômico, que funcionam como mecanismos de planejamento, controle transparência. Constatou-se que parcerias e benchmarkingsão cruciais para o desenvolvimento dos programas e projetos, associando-se a princípios da literatura de governo empreendedor. Desta forma, considera-se que a SDE fomenta práticas empreendedoras na gestão pública municipal.

Palavras-chave: Gestão pública municipal, Empreendedorismo público, Governo empreendedor, Controle.

\section{INTRODUÇÃO}

Para que a Administração Pública possa promover o atendimento das demandas da sociedade, suas atividades devem orientar-sepor resultados concretos. Contudo, o que se tem observado é que a gestão pública ainda sofre com as disfunções da burocracia. Além disso, são difusos os esforços por inovação. Tendo em vista às transformações tecnológicas, sociais, econômicas e ambientais que atingem atualmente o setor público, nota-se a necessidade de modernização da gestão, através da adoção de técnicas capazes de fazer com que os governos entendam as mudanças e saibam agir com respostas efetivas às demandas da sociedade.

Para Valadares e Emmendoerfer (2015), o processo de modernização tem se acentuado nas últimas décadas através de noções comportamentais e gerenciais intrínsecas às práticas empresariais. Entre estas noções está o empreendedorismo, fenômeno que tem sido empregado no contexto do setor público comoum importante mecanismo para a resolução de problemas, uma vez que é imbuído de características como a iniciativa e criação de novas oportunidades, criatividade, flexibilidade, dinamismo, inovação, entre outros aspectos (DORNELAS, 2015).

Diversos estudos têm enfatizado a importância deste fenômeno no ambiente governamental, destacando-se o clássico trabalho desenvolvido por Osborne e Gaebler, que impulsionaram o movimento "reinventando o governo". Segundo estes autores, os governos municipais foram os primeiros a reagir às novas realidades, incorporando ações consideradas inovadoras, nas quais abrangem princípios que vão desde o fomento à inclusão da sociedade nas decisões públicas até a focalização nos resultados (OSBORNE e GAEBLER, 1995).

É nesta abordagem que a Secretaria Municipal do Desenvolvimento Econômico de Fortaleza-CE (SDE), objeto de análise deste estudo, orienta seus esforços para a modernização de sua gestão e para a inovação nos serviços prestados aos cidadãos. Instituída com a finalidade de implementar ações de fomento ao desenvolvimento econômico autossustentável, a SDE se destaca por desenvolver diversas ações de incentivo ao empreendedorismo e a inclusão social.

Com base no exposto, observa-se a importância de se investigar a introdução de práticas empreendedoras no setor público, especialmente no âmbito da gestão municipal.A

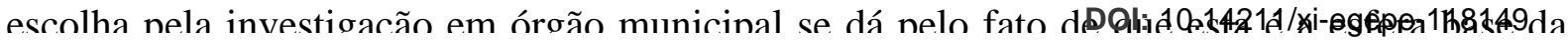


administração pública, configurando-se assim como o nível mais apropriado para se medir os impactos da introdução de práticas que colaborem para a eficiência governamental.Além do mais, enquanto no campo empresarial o empreendedorismo tem sido bastante discutido, no setor público ainda são poucas as pesquisas (VALADARES e EMMENDOERFER, 2015).

Mediante essa contextualização, definiu-se a seguinte questão de pesquisa: em que medida as práticas desenvolvidas pela SDE podem ser consideradas ações empreendedoras? Com o intuito de responder tal questão, o presente estudo tem por objetivo analisar a inserção de aspectos do empreendedorismo no setor público, por meio da análise das ações e ferramentas utilizadas na gestão da SDE.

Este trabalho está estruturado em cincoseções. Além desta parte introdutória, a seção 2 apresentada a base teórica do estudo. Na seção3 são apresentados os procedimentos metodológicos que nortearam a realização da pesquisa e uma breve descrição da SDE. Na seção 5 são apresentados os resultados obtidos com a análisedo caso da SDE. Por fim, são feitas considerações finais a respeito da investigação.

\section{EMPREENDEDORISMO: CONCEITUALIZAÇÃO E INSERÇÃO DO TERMO NO SETOR PÚBLICO}

Conceituar o termo empreendedorismo não se constitui tarefa fácil, visto que este se configura em um fenômeno multidisciplinar no campo das ciências sociais. Grosso modo, o empreendedorismo liga-se naturalmente a elementos como a inovação, investimentos, iniciativa, busca pela mudança, aproveitamento de oportunidades, aceitação de riscos, resolução criativa dos problemas, capacidade de decisão, persistência.

Para Schumpeter (1997), o empreendedorismo está associado ao desenvolvimento econômico, à inovação, à criação de novos mercados e à ação do empreendedor. As concepções schumpeterianas assinalam uma das teorias que abordam o empreendedorismo: a teoria econômica. A teoria comportamentalista, em que se destacam Weber e McClelland, evidencia a motivação e o comportamento humano (BAGGIO; BAGGIO, 2014). Ambas as teorias não se opõem, mas existem como ampliação uma da outra.

Para Dolabela (2008),empreender significa identificar oportunidades, inovar e buscar mudanças para que as organizações possam atingir e manter bom desempenho. $\mathrm{O}$ autor destaca o papel do empreendedorismo para o desenvolvimento econômico e social de uma região, uma vez que este não se configura em um fenômeno individual. Diversos estudos já apontam para o desprendimento do termo empreendedorismo do estrito campo econômicomercantil. Mello e Cordeiro (2010) percebem o empreendedorismo através da relação dinâmica entre a estrutura e a agência empreendedora, no sentido de possibilitar ao empreendedor recursos sociais, dado que se presume um compromisso entre sujeitos em uma situação de reconstrução social.

Pode-se considerar que a introdução do empreendedorismo na gestão pública se deu com o movimento gerencial de administração. Este modelo manifestou-se no contexto da crise econômica mundial da década de 70 (COSTIN, 2010). Segundo Abrucio (1997) o tipo de Estado que se constituía mediante a crise desta época tinha três dimensões. A primeira caracterizava-se pelo ideário keynesiano, defendendo-se a intervenção do Estado como uma forma de impulsionar o crescimento. A segunda, correspondente ao welfarestateque visava a geração de políticas públicas voltadas às áreas sociais. E por fim, a dimensão administrativa faz referência ao funcionamento interno do Estado, que se baseava no modelo burocrático.

Foi então a partir do esgotamento desta última dimensão, quando o modelo burocrático se mostroulimitado para atingir a eficiência dos processos administrativos, que surge a necessidade de uma nova forma de gerir a máquina pública (ABRUCIO, 1997).

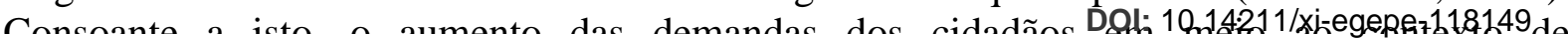


intensificação da globalização e difusão das tecnologias de informação(MATIAS-PEREIRA, 2010).

O modelo gerencial de administração foi responsável pela grande onda de reformas de Estados e pela inserção de práticas do empreendedorismo no setor público.No Brasil, a tentativa de introduzir os princípios gerencialistastambém se deu em um contexto de crise do Estado, que motivou a realização de uma Reforma administrativa no governo de Fernando Henrique Cardoso. Tal reforma baseou-se na criação do Ministério da Administração Federal e Reforma do Estado (MARE), que resultou na criação do Plano Diretor da Reforma do Estado. O modelo de administração gerencial que se buscava implantar teve por base três dimensões: a dimensão institucional-legal, a cultural e a dimensão gerencial. Apesar das diversas críticas à proposta, muitas medidas foram implementadas, como o estabelecimentode tetos para o gasto com o funcionalismo, o incremento da eficiência como mais um princípio da administração pública e alterações no Regime Jurídico Único (ABRUCIO, 2007).

Quanto às principais características deste modelo, Sanabio, Santos e David (2013) consideram que a administração gerencial se baseia na tomada de medidas orientadas para o aumento da eficiência, na atuação descentralizada, no controle dos resultados e na orientação ao cidadão, que é cliente dos serviços. É importante ressaltar que o modelo não encerra os princípios adotados anteriormente pela administração pública, especialmente os burocráticos.

\subsection{Empreendedorismo público na gestão municipal}

Apesar do empreendedorismo ter nascido e ser comumente aplicado no setor privado, sua utilização tem se apresentado na administração pública como um meio de modernização. Drucker (1987, p. 245) já afirmava que instituições de serviços públicos devem ser "tão empreendedoras e inovadoras quanto qualquer negócio", isto porque as mudanças tecnológicas, econômicas, de competição e de comunicação também incidem sobre as organizações públicas.

É relevante considerar as diferenças entre o setor privado e o setor público, uma vez que, mesmo que o empreendedorismo possa ser empregado em ambas as áreas, os aspectos inerentes a cada esfera não podem ser deslocados sem apropriada adequação. Segundo Moore (2002), estes campos distinguem-se principalmente no que diz respeito à geração de valor que é produzido.No entanto, ambos possuem a mesma problemática: o desafio de empreender.

Existem também diversas concepções para oempreendedorismo no campo da gestão pública. Para Sousa e Paiva Junior (2010, p. 4), o "empreendedorismo público é um processo de criação de valor para os cidadãos, de forma a trazer conjuntamente recursos públicos e privados combinados para explorar oportunidades sociais" o que gera benefícios tanto para os cidadãos, como também para as organizações. Teixeira e Teixeira (2004) ampliam esta análise para a gestão municipal, apontando que esta, amparada em preceitos tradicionais, como a excessiva racionalidade, estruturas organizacionais centralizadoras e autoritárias, não se adequa mais ao ambiente globalizado.É fundamental que os gestores municipais sejam capazes de formular, associado a outros agentes sociais, um plano estratégico local através da busca do que é de interesse da população.

Conforme Ceará (2005), para a gestão pública municipal tornar-se empreendedora é crucial o uso da inovação e a ação efetiva de gestores locais. Podem ser empreendedores públicos prefeitos, secretários e demais gestores de projetos(CEARÁ, 2015). Considerada a principal ferramenta dos empreendedores, a busca pela inovação resulta em governos mais atuantes, produtivos e mais próximos da população. Além disso, o bom andamento das gestões municipaismotiva outras administrações a adotarem práticas inovadoras. É importante salientar quea capacidade de empreender depende da cultura e características inerentes a cada onverno

DOI: $10.14211 /$ xi-egepe-118149 
Pode-se considerar que o empreendedorismo público foi bastante influenciado pelo movimento denominado "Governo Empreendedor" (PAULA, 2005). Este movimento foi intensificado na década de 90, nos Estados Unidos com a publicação do livro "Reinventando o governo: como o espírito empreendedor está transformando o setor público" deOsborne e Gaebler. A obra reúne diversas experiências de instituições públicas estadunidenses, com o intuito de demonstrar como os governos devem atuar para tornarem-se empreendedores.

Os autores reconhecem que não se é capaz de governar organizações públicas como quem dirige uma empresa. No entanto, isto não significa que as instituições públicas não possam se tornar mais empreendedoras (OSBORNE e GAEBLER, 1995). O Quadro 1 apresenta princípios indicados pelos autores para construção de um governo empreendedor.

\section{Quadro 1 - Princípios para um governo empreendedor}

\begin{tabular}{|c|c|}
\hline PRINCÍPIOS & ESTRATÉGIA \\
\hline Governo catalisador & $\begin{array}{l}\text { Os governos devem assumir, através de parcerias, a implementação de } \\
\text { políticas públicas, para que estas possam ser melhor prestadas à sociedade. }\end{array}$ \\
\hline $\begin{array}{l}\text { Governo pertencente à } \\
\text { comunidade }\end{array}$ & $\begin{array}{l}\text { Os governos devem transferir o controle das ações aos cidadãos, } \\
\text { incentivando-os a participar das decisões locais. }\end{array}$ \\
\hline Governo competitivo & $\begin{array}{l}\text { Os governos devem inserir a competição na prestação dos serviços públicos, } \\
\text { para que estes possam ser mais eficientes e com maior qualidade. }\end{array}$ \\
\hline $\begin{array}{l}\text { Governo orientado por } \\
\text { missões }\end{array}$ & $\begin{array}{l}\text { As instituições públicas devem orientar-se por sua verdadeira missão e não } \\
\text { por excessivas normas e regras. }\end{array}$ \\
\hline Governo de resultados & $\begin{array}{l}\text { Os governos devem utilizar mecanismos de avaliação de desempenho, } \\
\text { desconcentrando-se do controle dos recursos. }\end{array}$ \\
\hline $\begin{array}{l}\text { Governo orientado ao } \\
\text { cliente }\end{array}$ & $\begin{array}{l}\text { Os governos devem valorizar os cidadãos como clientes dos serviços } \\
\text { prestados, ouvindo-os, identificando e atendendo suas necessidades. }\end{array}$ \\
\hline Governo empreendedor & $\begin{array}{l}\text { Os governos devem investir na geração de receitas e não de despesas, } \\
\text { criando novas fontes de. }\end{array}$ \\
\hline Governo preventivo & $\begin{array}{l}\text { Os governos devem atuar preventivamente aos problemas, ao invés de } \\
\text { simplesmente repará-los, através do planejamento de suas ações. }\end{array}$ \\
\hline Governo descentralizado & $\begin{array}{l}\text { Os governos precisam descentralizar suas decisões, dando maior autonomia } \\
\text { aos servidores como forma de democratizar a gestão. }\end{array}$ \\
\hline $\begin{array}{l}\text { Governo orientado para o } \\
\text { mercado }\end{array}$ & $\begin{array}{l}\text { É fundamental que os governos induzam mudanças em suas estruturas por } \\
\text { meio da inserção de mecanismos e soluções utilizados pelo mercado. }\end{array}$ \\
\hline
\end{tabular}

Fonte: elaborado pela autora com base em Osborne e Gaebler (1995, p. 26-337).

Mediante ao exposto, observa-se que o empreendedorismo público ainda se configura em um conceito em construção, provocando debates quanto aos reais efeitos na administração pública. Embora os autores supracitados revelem que os efeitos benéficos, há quem considere que a prática não seja facilmente absorvida, uma vez que, o excesso de burocratização dificulta a inserção de uma cultura empreendedora (VALADARES; EMMENDOERFER, 2015). Na visão de Secchi (2009), há de se preocupar com o fato de que a imagem benéfica das ações empreendedoras pode ser utilizada como retórica por governantes e partidos políticos. Estes podem manipular a percepção da população, apłess:enfand $\rho_{1}$ tal prática 
instrumento de novidade e não se baseando em fatos concretos, na busca preservação do seu poder.

\section{METODOLOGIA DA PESQUISA}

Esta pesquisa possuicaráter qualitativo. Com relação à finalidade, conduziu-se para a pesquisa exploratória-descritiva.Quanto aos procedimentos, utilizou-se do estudo de caso únicocomo estratégia de investigação, centrando-se em um estudo da SDE de Fortaleza-CE.

Utilizou-se a pesquisa bibliográfica, a pesquisa documental e entrevista semiestruturada como técnicas de coleta.Fez-se uso da pesquisa documental como método para a coleta de legislações que incidem sobre as competências e objetivos da SDE; a organização administrativa da secretaria; einformações referentes às ferramentas, programas e projetos da SDE. Foram colhidas informações junto ao Coordenador de Projetos e Desenvolvimento Econômico da SDE através de entrevista semiestruturada na secretaria.

A técnica de análise de conteúdo foi empregada conforme Bardin (1977). Foi realizada a transcrição das informações da entrevista e, juntamente com os dados documentais, realizou-se a organização e análise dos dados, por meio das seguintes categorias analíticas: ferramentas de gestão utilizadas para o planejamento e controle das ações; programas e projetos desenvolvidos; estrutura administrativa e atividades internas;resultados e desafios na gestão.

\subsection{Descrição do objeto de análise: a SDE}

A Prefeitura de Fortaleza atua por meio de dezesseis secretarias, estando entre elas a Secretaria Municipal do Desenvolvimento Econômico (SDE). A SDE tem por objetivoimplantar e executar ações voltadas para o desenvolvimento econômico autossustentável, por meio da indução, incentivo à implementação e desenvolvimento de novos empreendimentos.

A secretaria deve promover ações que induzam o fortalecimento da estrutura produtiva, seja ela formal ou informal, dando suporte à concessão de flexibilidade e apoiando as infraestruturas para a instituição de empreendimentos. A secretaria possui o total de quarenta e dois cargos de admissão em comissão. A estrutura organizacional da SDE pode ser observadana Figura 1.

\section{Figura 1 - Organograma da SDE}

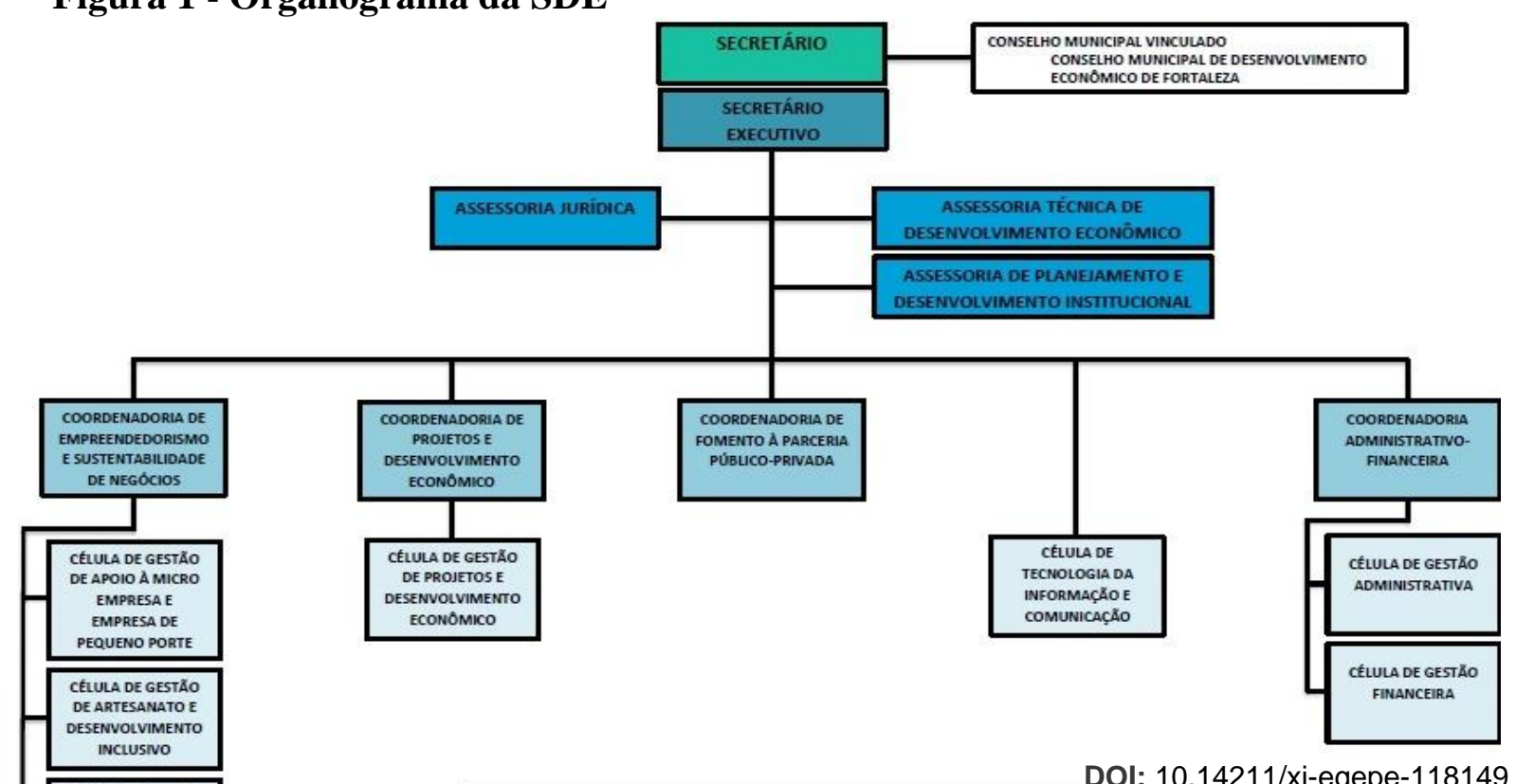

DOI: 10.14211/xi-egepe-118149 
Fonte: Decreto N 13.760/2016. Adaptado pela autora (2017)

A SDE atua com base em dois eixos: empreendedorismo e atração de investimentos. No primeiro, a secretaria busca promover ações direcionadas ao beneficiamento dos micro e pequenos empreendedores. No segundo eixo, a secretaria atua por meio, sobretudo, de incentivos fiscais (PREFEITURA DE FORTALEZA, 2016). A SDE realiza estudos que contribuem para a melhor formulação e implementação de suas ações. Dentre as pesquisas, destacam-se: Concentração Setorial de Empresas; Índice de Desenvolvimento Humano; Índice de Desenvolvimento Educacional.Para além dos estudos e pesquisas, a SDE promove diversos programas e projetos que serão detalhados na análise a seguir.

\section{ANÁLISE DAS PRÁTICAS E FERRAMENTAS UTILIZADAS PELA SDE COMO AÇÕES PÚBLICAS EMPREENDEDORAS}

Analisando-se os programas e projetos desenvolvidos pela SDE, constatou-se que estes são previstos e acompanhados através da ferramenta de gestão Monitoramento de Ações e Projetos Prioritários de Fortaleza (MAPPFOR), que é um sistema moderno de monitoramento dos projetos em execução e dos investimentos realizados pela Prefeitura de Fortaleza, reunindo uma série de informações sobre os projetos e o cronograma da execução física e fiscal de cada um deles. O MAPPFOR é utilizado por todos os órgãos da gestão municipal desde maio de 2013 e foi pensado a partir de um sistema desenvolvido em 2007, pelo governo do Estado do Ceará, denominado de Monitoramento de Ações e Projetos Prioritários (MAPP).

Além do MAPPFOR, uma outra ferramenta importante para a SDE é o Plano Fortaleza 2040: Construindo a Fortaleza que Queremos, que é um planejamento estratégico desenvolvido pela Prefeitura, voltado para o desenvolvimento econômico, social e urbanístico da cidade. Destaca-se o grande envolvimento de técnicos, pesquisadores, gestores e da população na formulação deste plano. Segundo o coordenador entrevistado, a participação social se concretiza neste projeto através dos comitês, conselhos e grupos de trabalho, sendo intrínseco à secretaria o Fórum da Micro e Pequena Empresa, realizado pela SDE em parceria com outros órgãos municipais e com instituições representantes dos micro e pequenos empreendedores.

Além disso, a SDE participa de diversos conselhos, como o Conselho Municipal do Trabalho e o Conselho Municipal do Turismo, e tem o seu próprio, que é o Conselho Municipal de Desenvolvimento Econômico. Com isso, estes mecanismos promovem, no âmbito da SDE, a participação social dentro do Plano Fortaleza 2040, reconhecendo-se que esta ação é essencial para a aplicação eficiente dos recursos públicos e para a formulação deste projeto. Conforme relata o coordenador: "tudo isso [...] congrega instituições que representam a sociedade civil organizada pra que possam sugerir, aprovar o uso do dinheiro da melhor forma possível".

Mediante a esta contextualização, pode-se observar, através do uso do sistema MAPPFOR e do Plano Fortaleza 2040, a demonstração de características empreendedoras. Ao se enfatizar a ferramenta de monitoramento dos projetos, observa-se o uso debenchmarking. Isto é observado quando a gestão municipal, vendo a implementaçãosatisfatória do sistema MAPP pelo governo do estado, elaborou a versão municipal deste sistema.

Nisto, constata-se também que dos princípios de Osborne e Gaebler (1995), confirma-

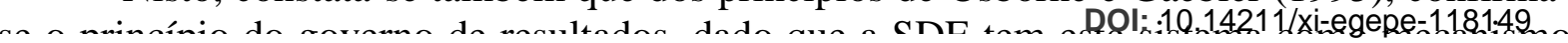


de monitoramento e avaliação do desempenho de seus projetos e ações.O coordenador afirma que:se eu começo a executar um projeto e ele não anda, eu sou cobrado por isso, a gestão me cobra: "você começou esse projeto, cadê os resultados dele?"[...] tudo que é feito tá registrado e tem uma estrutura de avaliação e monitoramento.

Observa-se ainda, o caráter inovador associado ao uso doMAPPFOR que este traz à gestão pública municipal. Governos empreendedores estão associados ao uso da inovação como método de os tornar mais atuantes, modernos e produtivos (CEARÁ, 2005). A utilização deste sistema de monitoramento das ações e resultados pouco se é vista no setor público.

Quanto ao Plano Fortaleza 2040, mais uma vez observa-se a adoção de uma técnica de um modelo de gestão empreendedor: a elaboração do planejamento estratégico municipal. Consoante a isto, a promoção do envolvimento da sociedade nas decisões públicas, aproxima a secretaria com o governo pertencente à comunidade e o governo orientado ao cliente, como apontam Osborne e Gaebler (1995). Tal fato é evidenciado quando o coordenador coloca:nós temos o Fortaleza 2040 que foi construído pela estrutura do município juntamente com a sociedade. Foi um trabalho de três anos consultando a sociedade em todas as áreas, que tipo de ação, que tipo de projeto deve ser desenvolvido no curto, médio e longo prazo.

No que diz respeito aos estudos realizados pela SDE, constatou-se que eles contribuíram para a geração de um banco de dados sobre as condições econômicas, de desenvolvimento humano e educacionais de Fortaleza, proporcionando um guia para os investidores, assim como uma orientação para a elaboração, planejamento e efetivação das políticas públicas municipais. Com isso, a SDE, apoiada nos resultados destes estudos, criou o projeto Mapeamento das Atividades Socioeconômicas, no qual reúne no portal da secretaria uma coleção de mapas que permitem a visualização das condições sociais e econômicas de cada bairro de Fortaleza.

Utilizando-se de técnicas de geoprocessamento, estes mapas estão disponibilizados através de softwares capazes de realizar o mapeamento socioeconômico por bairro, como por exemplo, o software Estoque de Empregos e Vínculos Empregatícios nos Bairros de Fortaleza; o software Índice de Desenvolvimento Humano (IDH) por Bairro; o software Indicadores Educacionais das Áreas de Ponderação de Fortaleza; entre outros softwares desenvolvidos.

Visto isso, o coordenador destaca que se pode ter como resultados concretos oriundos desta ferramenta, o aumento do número de atendimentos pela secretaria aos micro e pequenos empreendedores, assim como coloca: "nós tínhamos aqui uma meta, quando chegamos, de atender 30.000 micro empreendedores, mas já batemos 50.000 atendimentos". Em termos de geração de empregos, o coordenador destaca que, mesmo o país passando por um período de crise econômica, Fortaleza foi uma das capitais que mais gerou empregos formais no período que compreende os anos de 2013 a 2015, registrando apenas uma pequena queda no último ano.

Evidencia-se no exposto acima que a realização dos estudos e a consequente criação dos softwares de mapeamento socioeconômico dos bairros de Fortaleza confirmam mais uma ação empreendedora da SDE, dado que geraram um mecanismo inédito entre os municípios cearenses, aliado às técnicas de georreferenciamento, assim como expressa o coordenador: "esse sistema de mapeamento é uma tecnologia nova, uma inovação em termos de gestão. A gente procurou até em outras prefeituras e não encontrou nada semelhante". Estas ferramentas ainda se configuram como meios de promoção da transparência pública, pois, ao reunirem uma base de dados sobre a cidade, permite que a população tenha ciência de todas estas informações.

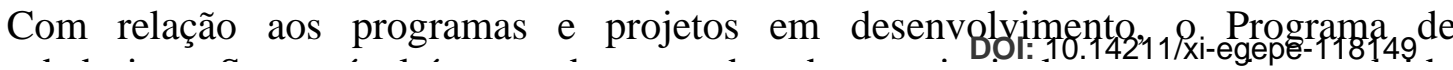


pela secretaria. Realizada em parceria com o Sebrae, a iniciativa tem fomentado a formalização, a sustentabilidade e a capacidade gerencial dos empreendedores de Fortaleza, e tem colocado a capital cearense em segundo lugar no Nordeste e sexto dentre as capitais do Brasil, no que tange à formalização de negócios (PREFEITURA DE FORTALEZA, 2016).

$\mathrm{Na}$ área da comercialização, o Programa Feiras de Pequenos Negócios de Fortaleza tem contribuído com a melhoria e a ampliação dos espaços para a venda dos produtos e serviços regionais produzidos pelos pequenos empreendedores, além de que proporciona capacitações gerenciais. Com essas ações, a secretaria já promoveu980 feiras, beneficiando cerca de 2 mil pequenos produtores. Segundo o coordenador: [...] apoiamos feiras que acontecem nos terminais de ônibus, acontecem em empresas, nas instituições, vez por outra tem uma aqui. [...] a gente dá o suporte [...] com o material físico que eles [os empreendedores] usam.

O Projeto Meu Carrinho Empreendedor é direcionado aos vendedores ambulantes de pipoca. Estes são oportunizados a substituir seus antigos carrinhos por novos customizados pela prefeitura, através da SDE, tornando os negócios formalizados e mais atrativos. Desenvolvido com o apoio de diversas parcerias, o projeto foi lançado em novembro de 2015 com uma meta de atingir mais de 150 vendedores, estando ainda em fases iniciais de execução.

A respeito do Projeto Incubadora de Economia Criativa, implementado no final do ano de 2014, a SDE atua como incentivadora do empreendedorismo entre jovens de16 a 29 anos: "é um trabalho que a gente vem fazendo pra impulsionar a criação de startups. Então nós temos muitas boas ideias que começam com pequenos empreendedores e que eles não têm muito suporte", expressa o coordenador quando também cita o tipo de suporte que é dado aos jovens empreendedores: "[...] eles têm um ambiente fisico, uma sala com computador, com mesa, com telefone disponível, internet, e nós damos capacitações [...] e consultorias técnicas".

No que tange ao Projeto Visão nas Mãos, este ampliou os espaços de trabalho dos massoterapeutas deficientes visuais da cidade de Fortaleza que antes concentravam-se apenas em um único local da cidade. De acordo com o coordenador, um dos objetivos é que, com as capacitações e os materiais de trabalho ofertados pela secretaria, os massoterapeutas possam desenvolver futuramente sua própria empresa.

Mediante os resultados dos programas e projetos da SDE, percebe-se notável potencial empreendedor em relação as ações da secretaria. No tocante às parcerias, percebe-se uma gestão catalisadora, conforme o princípio do governo catalisador evidenciado por Osborne e Gaebler (1995).As parcerias com as instituições voltadas para os micro e pequenos empreendedores, as demais secretarias do município e as instituições financeiras, colaboram para a abertura do microcrédito e demais vantagens para este público. O coordenador reconhece a importância destas parcerias: "sem as parcerias a gente não consegue executar o que a gente vem fazendo. Então nós não temos recursos pra fazer tudo que precisa, sabemos que tem muita coisa a fazer ainda e sem os parceiros a gente não consegue andar. [...] A parceria é muito importante".

Pode-se também considerar os programas e projetos da SDE como ações empreendedoras porque além de serem discutidos previamente com a população, também é realizado o benchmarking com outros órgãos municipais para implementação no município de Fortaleza: "em geral, sempre que a gente vai aplicar algum projeto aqui, a gente consulta outros lugares, a gente pesquisa bastante pra ver onde é que deu certo, [...] conversa com quem já aplicou algo semelhante", ressalta o coordenador da SDE.

Para além das ferramentas utilizadas para melhorar a gestão da SDE e as políticas de desenvolvimento econômico realizadas, algumas mudanças em sua estrutura física foram 
transferência da sede da SDE, que antes estava instalada em condições precárias, para um ambiente com novos equipamentos, boa iluminação, boa conexão com a internet através da Rede Metropolitana de Fortaleza (GigaFor) e o novo layout no qual a secretaria está organizada, dado que as salas de trabalho se organizam emespaços conectados e abertos, em que todos podem interagir entre si.

Diante destas mudanças, constatou-se que a estrutura de trabalho dos gestores exerce grande influência no modo que estes irão desenvolver suas atividades. Conforme aponta o coordenador: "nós trabalhávamos numa sede bem deteriorada e estamos talvez em um dos prédios mais modernos da prefeitura hoje e isso cria um ambiente totalmente diferenciado de trabalho". Tal fato condiz com o que é evidenciado pela literatura, quando Rezende (2006) constata que o espírito empreendedor dos gestores municipais é despertado principalmente por sua força de vontade, no entanto, incentivos também estimulam seus traços empreendedores. Além disso, estes incentivos, como melhores espaços de trabalho na SDE, coadunam com os princípios deOsborne e Gaebler (1995), uma vez que estas iniciativas motivam seus colaboradores, proporcionam diminuição dos custos e maior rapidez nas decisões.

Outra significativa mudança decorreu da descentralização dos serviços que são prestados pela SDE, com a instituição da Unidade Móvel que percorre os bairros de Fortaleza, oferecendo os mesmos serviços disponibilizados na Sala do Empreendedor. O serviço itinerante facilita o acesso dos micro e pequenos empreendedores aos serviços ofertados: " $a$ gente descentralizou pra atender os pequenos que tem uma dificuldade maior de locomoção, como a cidade é muito grande". A criação da Unidade caracteriza a gestão da SDE voltada para os cidadãos, confirmando o princípio orientação ao cliente de Osborne e Gaebler (1995).

Por fim, na perspectiva da secretaria analisada, constatou-se que embora as ferramentas e políticas desenvolvidas demonstrem êxito em sua efetivação, a SDE também sofre com as disfunções da burocracia, assim como elenca o próprio coordenador: "sempre que se trabalha na Administração Pública, a burocracia, ela tem que ser levada em conta. Não é que coloque em risco, ela tardia o resultado, tardia a execução. É uma premissa certa". No entanto, mesmo os entraves burocráticos, os resultados apresentados confirmam a abrangência das ferramentas e ações do órgão analisado como de grande importância no âmbito da administração municipal, revelando sua vocação para a inovação e características empreendedoras.

\section{CONSIDERAÇÕES FINAIS}

Esta pesquisa teve como objetivo analisar a inserção de aspectos do empreendedorismo no setor público, por meio da análise das ações e ferramentas utilizadas na gestão da Secretaria Municipal do Desenvolvimento Econômico de Fortaleza-CE (SDE). Na medida em que a secretaria faz uso de ferramentas de planejamento e controle das ações, como o Plano Fortaleza 2040 e o MAPPFOR, constata-se características de um governo que pretende ser empreendedor.

Constatou-se que as ferramentas identificadas levam a gestão da SDE a princípios apontados por Osborne e Gaebler (1995) quando aproximam a comunidade de suas decisões (governo pertencente à comunidade e governo orientado ao cliente) e focalizam os resultados das ações e não de seus processos (governo de resultados). Ademais, essas iniciativas somadas à realização debenchmarking com adequação ao contexto da secretaria; às parcerias firmadas pela SDE;às mudanças ocorridas na sede da secretaria, quanto a sua instalação e organização, exercem influência no desenvolvimento de suas características empreendedoras.

Os projetos de cunho social-econômicos se configuram em in iniciativas singulares da 
O apoio obtido de outras instituições confirma o governo catalisador evidenciado por Osborne e Gaebler (1995), quando colocam que, atuando de maneira conjunta, os governos conseguem melhor solucionar e atender as demandas da população. No entanto, é necessário ressaltar que, embora a discussão em torno do empreendedorismo no setor público o denote como possível solucionador dos excessos burocráticos nas instâncias municipais, é preciso que sejam realizadas análises mais aprofundadas para a descoberta e difusão de outros benefícios ou desvantagens que a inserção deste fenômeno pode trazer ao setor público, dado aincipiência de estudos sobre o tema.

\section{REFERÊNCIAS}

ABRUCIO, F. L. O impacto do modelo gerencial na administração pública: um breve estudo sobre a experiência internacional recente. Cadernos Enap, Brasília, n. 10, 1997.

ABRUCIO, F. L. Trajetória recente da gestão pública brasileira: um balanço crítico e a renovação da agenda de reformas. Revista de Administração Pública, Rio de Janeiro, p.6786, jun. 2007.

BAGGIO, A. F.; BAGGIO, D. K. Empreendedorismo: Conceitos e definições. Revista de Empreendedorismo, Inovação e Tecnologia, [S.1.], v. 1, n. 1, p. 25-38, 2014.

BARDIN, L. Análise de conteúdo. São Paulo: Edições 70, 1977.

CEARÁ. Município Empreendedor: políticas públicas de trabalho, renda e empreendedorismo. Fortaleza: Secretaria do Trabalho e Empreendedorismo, 2005.

COSTIN, C. Administração Pública. Rio de Janeiro: Elsevier, 2010. 260 p.

DOLABELA, F. Oficina do empreendedor. Rio de Janeiro: Sextante, 2008.

DORNELAS, J. C. A. Empreendedorismo: transformando ideias em negócios. 5. ed. Rio de Janeiro: Empreende/LTC, 2015.

FORTALEZA. Decreto no 13.760, de 07 de março de 2016. Altera denominação dos cargos em comissão da Secretaria Municipal do Desenvolvimento Econômico (SDE), na forma que indica. Fortaleza, CE.

FORTALEZA. Lei Complementar n⿳ 176, de 19 de dezembro de 2014. Dispõe sobre a organização e a estrutura administrativa do Poder Executivo Municipal e dá outras providências.

MATIAS-PEREIRA, J. Curso de Administração Pública: foco nas instituições e ações governamentais. 3. ed. São Paulo: Atlas, 2010.

MELLO, S. C. B.; CORDEIRO, A. T. Investigando novas articulações e possibilidades no discurso empreendedor: contexto, sujeito e ação. Organizações \& Sociedade, Salvador, v. 17, n. 53, p.279-295, 2010. Trimestral.

MOORE, M. H. Criando valor público: gestão estratégica no governo. Rio de Janeiro: Letras e Expressões, 2002.

OLIVEIRA, F. M. de. Empreendedorismo: teoria e prática. Especialize, [S.1], p.1-13, maio 2012.

OSBORNE, D.; GAEBLER, T. Reinventando o governo: como o espírito empreendedor está transformando o setor público. 6. ed. Brasília: MH Comunicação, 1995. 436 p.

PAULA, A. P. P. de. Por uma nova gestão pública: limites e potencialidades da experiência contemporânea. Rio de Janeiro: Editora FGV, 2005. 204 p. 
PREFEITURA DE FORTALEZA. 2016. Disponível em: 〈https://www.fortaleza.ce.gov.br/> . Acesso em: 08 mar. 2017.

REZENDE, D. A. Planejamento estratégico municipal como proposta de desenvolvimento local e regional de um município paranaense. Revista da FAE, Curitiba, v. 9, n. 2, p.87-104, 2006.

SANABIO, M. T.; SANTOS, G. J. dos; DAVID, M. V. (Org.). Administração pública contemporânea: política, democracia e gestão. Juiz de Fora: Ed. Ufjf, 2013. 246 p.

SCHUMPETER, J.A. Teoria do desenvolvimento econômico: uma investigação sobre lucros, capital, crédito, juro e o ciclo econômico. Tradução: Maria Sílvia Possas.

Disponibilização: Ronaldo DartVeiga. São Paulo: Editora Nova Cultural, 1997. 238 p.

SECCHI, L. Modelos organizacionais e reformas da administração pública. Revista de Administração Pública, Rio de Janeiro, v. 43, n. 2, p.347-369, jan. 2009.

SOUSA, J. L. de; PAIVA JUNIOR, F. G. de. O empreendedorismo no setor público: a ação empreendedora da Fundação Joaquim Nabuco. In: Encontro de Administração Pública e Governança. Anais...Vitória, 2010. p. 1-16.

TEIXEIRA, I. S.; TEIXEIRA, R. C. F.da S. A gestão pública e o seu papel social e ambiental. In: Simpósio de Excelência em Gestão e Tecnologia. Anais... Rio de Janeiro, 2004. p. 1-16.

VALADARES, J. L.; EMMENDOERFER, M. L. A Incorporação do Empreendedorismo no Setor Público: reflexões baseadas no contexto brasileiro. Revista de Ciências da Administração, Florianópolis, v. 17, n. 41, p.8298, abr. 2015. 